\title{
The calculated and observed ionospheric properties during Atmospheric Explorer-C satellite crossings over Millstone Hill
}

\author{
R. G. RoBle \\ National Center for Atmospheric Research, ${ }^{*}$ Boulder, Colorado 80307, U.S.A.
}

A. I. STEwART

Laboratory of Atmospheric and Space Physics, University of Colorado, Boulder, Colorado 80309, U.S.A.

\author{
M. R. TORR and D. W. RusCH
}

Space Physics Research Laboratory, Department of Atmospheric and Oceanic Sciences, University of Michigan, Ann Arbor, Michigan 48105, U.S.A.

and

\section{R. H. WAND}

Lincoln Laboratory, Massachusetts Institute of Technology Lexington, Massachusetts 02173, U.S.A.

(Received 14 April 1977)

\begin{abstract}
The Atmospheric Explorer-C (AE-C) satellite passed almost directly over the Millstone Hill incoherent scatter radar station on 14 February 1974 and passed within the near vicinity of the station on 15 February 1974. Measurements of ionospheric and atmospheric properties were made simultaneously by the incoherent scatter radar and the AE-C satellite instruments. The incoherent scatter radar measured vertical profiles of the electron and ion temperatures and electron density and these data were used to derive a neutral gas temperature profile. The AE-C satellite measured the electron and ion densities and electron and ion temperatures, neutral gas composition, solar EUV flux, photoelectron spectra, the $6300 \AA$ volume emission rate profile and the distribution of NO along the satellite path. These simultaneous measurements provide a consistent set of data to examine current $F$-region theory in the daytime ionosphere. We used a time-dependent coupled model of the ionospheric $E$ - and $F$-region to calculate the ionospheric properties over Millstone Hill at the times of the AE-C crossings and then compared the calculated structure to the observed structure. The results show good agreement between the incoherent scatter radar measurements and the model calculations. There is also good agreement among satellite and incoherent scatter radar measurements and model calculations for the altitude of the satellite crossing, $161 \mathrm{~km}$. The satellite measurements along the orbital path, however, reveal considerable horizontal gradients in the measured ionospheric properties.
\end{abstract}

\section{INTRODUCTION}

On 14 February 1974 (on orbit 666) the Atmospheric Explorer-C (AE-C) satellite (Dalgarno et al., 1973) passed within $59 \mathrm{~km}$ horizontal distance of the incoherent scatter radar station at Millstone Hill, Massachusetts $\left(42.6^{\circ} \mathrm{N}, 71.5^{\circ} \mathrm{W}\right)$, and on 15 February 1974 (on orbit 677 ) the satellite passed within $254 \mathrm{~km}$ horizontal distance of the station. Satellite and incoherent scatter radar data on the ionospheric and atmospheric properties were obtained simultaneously in nearly the same spatial regions and at the same time of day on each satellite pass. The incoherent scatter radar meas-

* The National Center for Atmospheric Research is sponsored by the National Science Foundation. ured the vertical profiles of electron density and electron and ion temperatures; the vertical distribution of neutral gas temperature and the exospheric temperature were derived from these data. The AE-C satellite measured the electron and ion temperatures, electron and ion densities, neutral gas composition and photoelectron spectra along the satellite path. In addition, measurements were made of the solar EUV and UV fluxes, the vertical profile of the $6300 \AA$ airglow volume emission rate and the vertical profile of the NO number density. These simultaneous satellite and incoherent scatter radar measurements provided a consistent set of data that we used to examine our understanding of $E$ - and $F$-region theory by comparing the data to model calculations. 
The ionospheric model used to calculate the ionospheric properties over Millstone Hill at the time of the AE-C satellite crossing has been described in detail by ROBLE (1975), STORARSKI et al. (1975) and RoBle et al. (1976). The model was expanded recently to include auroral processes, as described by RoBle and ReEs (1977), and to calculate the distribution of the minor neutral constituents $\mathrm{N}\left({ }^{2} D\right), \mathrm{N}\left({ }^{4} S\right)$ and NO. The ionospheric model was also modified to include the reaction rates, cross sections, etc., that were derived from previous AE-C studies. The satellite crossings over Millstone Hill occurred near 1130 LT. Therefore, the thermal and chemical properties of the midlatitude daytime ionospheric $E$ - and $F$-regions were calculated with the model and compared to measurements made by the AE-C satellite and Millstone Hill incoherent scatter radar.

Our results indicate that current ionospheric $E$ and $F$-region theory is adequate for describing the gross ionospheric and atmospheric properties over Millstone Hill on the two days when radar and satellite data were obtained simultaneously. Reasonable agreement between the calculated and observed values was obtained for the electron and ion temperatures, electron and ion densities, $6300 \AA$ volume emission rate profile, NO number density profile and photoelectron spectra on both satellite passes of Millstone Hill. The satellite observations show considerable latitudinal gradients in the measured properties, thereby indicating that caution is necessary in the derivation of vertical profiles of ionospheric properties from satellite measurements along the orbital path.

\section{IONOSPHERIC MODEL}

The ionospheric model used in these calculations is an extension of the model described by RoBLE (1975), StOlarski et al. (1975) and Roble et al. (1976). A block diagram of the model is shown in Fig. 1. Because most of the processes within the model have been described previously, we only discuss the modifications and additions made for this study. The main addition to the model is the inclusion of minor neutral constituent chemistry and coupling with direct particle precipitation in auroral processes, as discussed by RoBle and ReEs (1977).

The ion chemistry in the model was updated from that given in Table 1 of Roble (1975) to include many of the processes analyzed by the

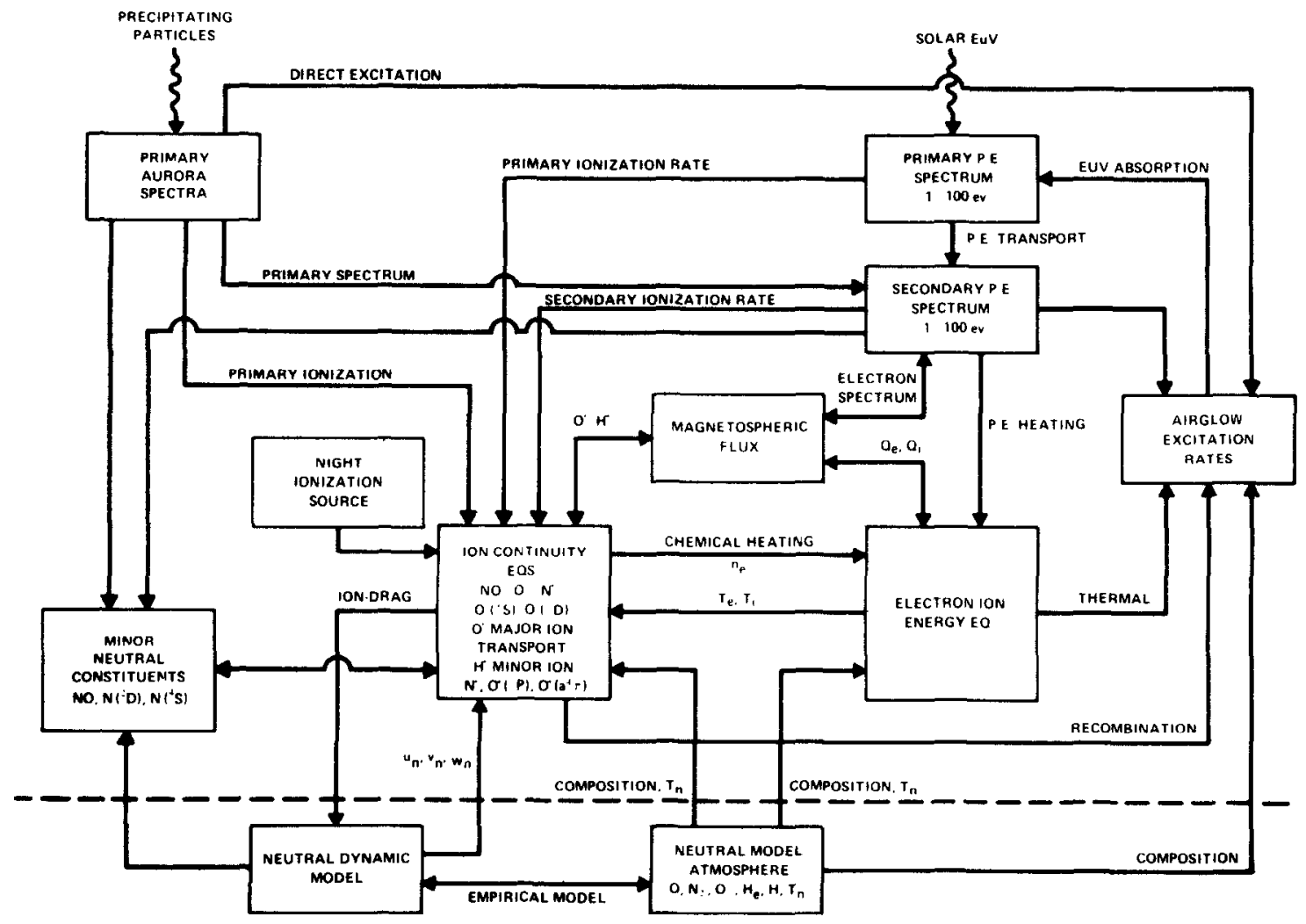

Fig. 1. Block diagram of ionospheric model. 
Table 1. Ion and neutral chemistry for midlatitude ionsopheric model

\begin{tabular}{|c|c|c|}
\hline Reaction & Reaction rate $\left(\mathrm{cm}^{3} \mathrm{~s}^{-1}\right)$ & Reference \\
\hline $\begin{array}{l}\mathrm{O}_{2}^{+}+\mathrm{N}_{2} \rightarrow \mathrm{NO}^{+}+\mathrm{NO} \\
\mathrm{O}_{2}^{+}+\mathrm{NO} \rightarrow \mathrm{NO}^{+}+\mathrm{O}_{2} \\
\mathrm{O}_{2}^{+}+\mathrm{N}\left({ }^{2} \mathrm{D}\right) \rightarrow \mathrm{N}^{+}+\mathrm{O}_{2} \\
\mathrm{O}_{2}^{+}+e \rightarrow \mathrm{O}+\mathrm{O}\left({ }^{3} P,{ }^{2} \mathrm{D},{ }^{1} \mathrm{~S}\right)[\mathrm{B} 1]\end{array}$ & $\begin{array}{c}5 \times 10^{-16} \\
4.4 \times 10^{-10} \\
2.5 \times 10^{-10} \\
1.1 \times 10^{-5} T_{e}^{-0.7} \text { for } T_{e} \leq 1000 \mathrm{~K} \\
1.6 \times 10^{-7}\left(T_{e} / 300\right)^{-0.55} ; T_{e}>1000 \mathrm{~K}\end{array}$ & $\begin{array}{l}\text { FERGUSON (1974) } \\
\text { LINDINGER et al. }(1975) \\
\text { DALGARNO (1970) }\end{array}$ \\
\hline $\begin{array}{l}\mathrm{O}_{2}^{+}+\mathrm{N}\left({ }^{4} \mathrm{~S}\right) \rightarrow \mathrm{NO}^{+}+\mathrm{O} \\
\mathrm{NO}^{+}+e \rightarrow \mathrm{O}+\mathrm{N}\left({ }^{2} \mathrm{D},{ }^{4} \mathrm{~S}\right)[\mathrm{B} 3]\end{array}$ & $\begin{array}{c}1.8 \times 10^{-10} \\
5 \times 10^{-7}\left(T_{e} / 300\right)^{-1.0} \text { for } T_{c}>1000 \mathrm{~K} \\
4.2 \times 10^{-7}\left(T_{e} / 300\right)^{-0.85} ; T_{\varepsilon} \leq 1000 \mathrm{~K}\end{array}$ & $\begin{array}{l}\text { GoLDAN et al. 1966) } \\
\text { TORR et al. (1976) }\end{array}$ \\
\hline $\mathrm{O}^{+}\left({ }^{4} \mathrm{~S}\right)+\mathrm{H} \rightarrow \mathrm{H}^{+}+\mathrm{O}$ & $6.0 \times 10^{-10}$ & FERGUSON (1974) \\
\hline $\begin{array}{l}\mathrm{O}^{+}\left({ }^{4} \mathrm{~S}\right)+\mathrm{N}_{2} \rightarrow \mathrm{NO}^{+}+\mathrm{N}\left({ }^{4} \mathrm{~S}\right) \\
\mathrm{O}^{+}\left({ }^{4} \mathrm{~S}\right)+\mathrm{O}_{2} \rightarrow \mathrm{O}_{2}^{+}+\mathrm{O}\end{array}$ & $\begin{array}{c}5.0 \times 10^{-13} ; T_{R}<1000 \mathrm{~K} \\
4.5 \times 10^{-14}\left(T_{R} / 300\right)^{2} ; T_{R} \geq 1000 \mathrm{~K} \\
2.0 \times 10^{-11}\left(T_{R} / 300\right)^{-0.4} ; T_{R}<1800 \mathrm{~K}\end{array}$ & LiNDINGER et al. (1974) \\
\hline & $1.3 \times 10^{-12}\left(T_{R} / 300\right)^{-1.2} ; T_{R} \geq 1800 \mathrm{~K}$ & MCFARLAND et al. (1973) \\
\hline $\begin{array}{l}\mathrm{O}^{+}\left({ }^{4} S\right)+\mathrm{NO} \rightarrow \mathrm{NO}^{+}+\mathrm{O} \\
\mathrm{O}^{+}\left({ }^{2} \mathrm{D}\right)+\mathrm{N}_{2} \rightarrow \mathrm{NO}^{+}+\mathrm{N}\left({ }^{4} S\right)\end{array}$ & $\begin{array}{c}8 \times 10^{-13} \\
5.6 \times 10^{-13} \text { for } T_{R}<1000 \mathrm{~K}\end{array}$ & $\begin{array}{l}\text { FERGUSON (1974) } \\
\text { LINDINGER (1974) }\end{array}$ \\
\hline $\begin{array}{l}\mathrm{O}^{+}\left({ }^{2} \mathrm{D}\right)+e \rightarrow \mathrm{O}^{+}\left({ }^{4} \mathrm{~S}\right)+e \\
\mathrm{O}^{+}\left({ }^{2} \mathrm{D}\right)+\mathrm{N}_{2} \rightarrow \mathrm{N}_{2}^{+}+\mathrm{O} \\
\mathrm{N}_{2}^{+}+\mathrm{O}_{2} \rightarrow \mathrm{O}_{2}^{+}+\mathrm{N}_{2}\end{array}$ & $\begin{array}{c}7.8 \times 10^{-8}\left(300 / T_{e}\right)^{1 / 2} \\
1.0 \times 10^{-9} \\
5.0 \times 10^{-11}\left(T_{R} / 300\right)^{-0.8} ; T_{R}<3560 \mathrm{~K}\end{array}$ & $\begin{array}{l}\text { HENRY et al. (1969) } \\
\text { RUTHERFORD and VROOM (1971) } \\
\text { LINDINGER et al. (1974) }\end{array}$ \\
\hline $\mathrm{N}_{2}^{+}+\mathrm{O} \rightarrow \mathrm{NO}^{+}+\mathrm{N}\left({ }^{2} \mathrm{D},{ }^{4} \mathrm{~S}\right)[\mathrm{B} 2]$ & $\begin{array}{c}1.4 \times 10^{-10}\left(T_{R} / 300\right)^{-0.44}\left[1-0.07\left(T_{R} / 300\right)^{0.21}\right] ; T_{R}<1500 \mathrm{~K} \\
5.2 \times 10^{-11}\left(T_{R} / 300\right)^{0.2}\left[1-0.07\left(T_{R} / 300\right)^{0.21}\right] ; T_{R} \geq 1500 \mathrm{~K}\end{array}$ & McFARLAND et al. (1974) \\
\hline $\mathrm{N}_{2}{ }^{+}+e \rightarrow \mathrm{N}+\mathrm{N}\left({ }^{4} S,{ }^{2} D\right)[\mathrm{B} 4]$ & $\begin{array}{c}1.8 \times 10^{-7}\left(T_{v} / T_{e}\right)^{-0.4} \\
1.4 \times 10^{-10}\left(T_{R} / 300\right)^{-0.44} \cdot G .07\left(T_{R} / 300\right)^{0.21} ; T_{R}<1500 \mathrm{~K}\end{array}$ & $\begin{array}{l}\text { ORSINI et al. (1976) } \\
\text { MCFARLAND et al. (1974) }\end{array}$ \\
\hline $\mathrm{N}_{2}^{+}+\mathrm{O} \rightarrow \mathrm{O}^{+}+\mathrm{N}_{2}$ & $5.2 \times 10^{-11}\left(T_{R} / 300\right)^{0.2} \cdot 0.07\left(T_{R} / 300\right)^{0.21} ; T_{R} \geq 1500 \mathrm{~K}$ & MCFARLAND et at. (19/4) \\
\hline $\mathrm{N}_{2}^{+}+\mathrm{NO} \rightarrow \mathrm{NO}^{+}+\mathrm{N}_{2}$ & $3.3 \times 10^{-10}$ & FEHSENFELD et al. (1970) \\
\hline $\mathrm{H}^{+}+\mathrm{O} \rightarrow \mathrm{O}^{+}+\mathbf{H}$ & $6.0 \times 10^{-10} \frac{8}{9}\left(\frac{T_{i}+T_{n} / 16}{T_{n}+T_{2} / 16}\right)^{1 / 2}$ & BANKS (1967) \\
\hline $\mathrm{N}\left({ }^{2} \mathrm{D}\right)+\mathrm{O}_{2} \rightarrow \mathrm{NO}+\mathrm{O}$ & $5.0 \times 10^{-12}$ & LIN and KAUFMAN (1971) \\
\hline $\mathrm{N}\left({ }^{2} \mathrm{D}\right)+\mathrm{O} \rightarrow \mathrm{N}\left({ }^{4} \mathrm{~S}\right)+\mathrm{O}$ & $<4.5 \times 10^{-13}$ & $\begin{array}{l}\text { ORAN et al. (1975) } \\
\text { FREDERICK and RUSCH (1977) }\end{array}$ \\
\hline $\mathrm{N}\left({ }^{2} \mathrm{D}\right)+e \rightarrow \mathrm{N}\left({ }^{4} S\right)+e$ & $1.0 \times 10^{-9}\left(T_{c} / 300\right)^{1 / 2}$ & Rusch et al. (1975) \\
\hline $\mathrm{N}\left({ }^{2} D\right)+\mathrm{NO} \rightarrow \mathrm{N}_{2}+\mathrm{O}$ & $7 \times 10^{-11}$ & BLACK et al. (1969) \\
\hline $\mathrm{N}\left({ }^{4} \mathrm{~S}\right)+\mathrm{O}_{2} \rightarrow \mathrm{NO}+\mathrm{O}$ & $2.4 \times 10^{-11} \exp \left(-3975 / T_{n}\right)$ & WILSON (1967) \\
\hline $\mathrm{N}\left({ }^{4} S\right)+\mathrm{NO} \rightarrow \mathrm{N}_{2}+\mathrm{O}$ & $1.5 \times 10^{-12} T_{n}^{1 / 2}$ & Phillips and SCHIFF (1962) \\
\hline $\mathrm{NO}+h \nu \rightarrow \mathrm{N}\left({ }^{4} S\right)+\mathrm{O}$ & $8.3 \times 10^{-6}$ & STROBEL (1971) \\
\hline $\mathrm{NO}+h \nu \rightarrow \mathrm{NO}^{+}+e$ & $6.0 \times 10^{-7}$ & STROBEL (1971) \\
\hline $\begin{array}{l}\mathrm{N}_{2}+e(\text { fast }) \rightarrow \mathrm{N}\left({ }^{4} S\right)+\mathrm{N}\left({ }^{2} \mathrm{D}\right)[\mathrm{B} 5] \\
\mathrm{N}\left({ }^{2} D\right) \rightarrow \mathrm{N}\left({ }^{4} S\right)+h v\end{array}$ & $1.06 \times 10^{-5}$ & $\begin{array}{l}\text { WINTERS }(1966) \\
\text { GASTRANG (1956) }\end{array}$ \\
\hline
\end{tabular}

$T_{e}=$ electron temperature $(K)$

$T_{i}=$ ion temperature $(K)$

$T_{v}=$ vibrated temperature $(\mathrm{K})$

$T_{R}=$ relative reactant kinetic temperature $(\mathrm{K})$

AE-C team. The ion chemistry currently in the model is summarized in Table 1 , along with the various reaction rates. The branching ratios for various chemical reaction rates are given in Table 2.

The minor neutral gas chemistry for $\mathrm{N}\left({ }^{4} S\right)$, $\mathrm{N}\left({ }^{2} D\right)$ and $\mathrm{NO}$ is also given in Table 1 . The diffusion equation that is solved for the minor neutral constituents is the same as that used by Strobel (1971), Rusch et al. (1975) and Oran et al. (1975). The coupled diffusion equations for $\mathrm{N}\left({ }^{4} S\right), \mathrm{N}\left({ }^{2} D\right)$ and $\mathrm{NO}$, with the chemical reactions given in Table 1 , are solved simultaneously at each time step according to the technique of Hastings and RoBLe (1977).
Although the solar EUV flux is routinely measured on board the AE-C sateilite (HINTEREGGER, 1976), no direct measurements were made for the particular days under consideration. The solar $F 10.7 \mathrm{~cm}$ flux values are $78.3 \times 10^{-22}$ and $85.8 \times 10^{-22} \mathrm{~W} \mathrm{~m}^{-2} \mathrm{~Hz}^{-1}$ for 14 and 15 February respectively (Table 3 ). For this level of solar activity we use the AE-C solar flux reference spectrum discussed by HiNTEREgGer (1975) in our calculations. The Hinteregger reference spectrum was obtained from a rocket flight on 23 April 1974, and the solar flux values are similar to those given in Hinteregger (1970). The solar EUV flux measurements available in the AE-C data file show that the values measured before and after 14 and 15 
Table 2. Branching ratios for reactions labelled (B-)

$$
\begin{aligned}
\text { (B1)_Production of } \mathrm{O}\left({ }^{1} D\right) & =1.0 \\
\mathrm{O}\left({ }^{1} S\right) & =0.04 \\
\mathrm{O}\left({ }^{3} P\right) & =0.96 \\
\text { (B2)_Production of } \mathrm{N}\left({ }^{4} S\right) & =0.05 \\
\mathrm{~N}\left({ }^{2} D\right) & =0.95 \\
\text { (B3)_Production of } \mathrm{N}\left({ }^{4} S\right) & =0.26 \\
\mathrm{~N}\left({ }^{2} \mathrm{D}\right) & =0.74 \\
\text { (B4)_Production of } \mathrm{N}\left({ }^{4} S\right) & =1.0 \\
\mathrm{~N}\left({ }^{2} D\right) & =1.0 \\
\text { (B5)_Production of } \mathrm{N}\left({ }^{4} S\right) & =1.0 \\
\mathrm{~N}\left({ }^{2} D\right) & =1.0
\end{aligned}
$$

February are very similar to the AE-C reference spectrum. Therefore, for the period during which solar flux values were not measured, it is reasonable to use the $A E-C$ reference spectrum in our calculations.

We use the satellite measurements of the neutral composition over Millstone Hill at an altitude
$161 \mathrm{~km}$ for our model calculations. The measurements for both days are given in Table 3 . The neutral gas temperature profile is determined from incoherent scatter radar data and is fit to the analytic temperature function specified by BATEs (1959) for model calculations. The profile is defined by an exosphcric temperature, the tcmpcrature at $120 \mathrm{~km}$ and the 'shape parameter, $S$,' that specified the temperature gradient in the lower thermosphere. These values are all given in Table 3 for both

\begin{tabular}{|c|c|c|}
\hline $\begin{array}{l}\text { AE orbit number } \\
\text { Date } \\
\text { Universal time, } \mathrm{Hr} \\
\text { EST, } \mathrm{Hr}\end{array}$ & $\begin{array}{l}666 \\
14 \text { Feb. } 1974 \\
1634 \\
1134\end{array}$ & $\begin{array}{l}677 \\
15 \text { Feb. } 1974 \\
1614 \\
1114\end{array}$ \\
\hline Altitude of crossing, $\mathrm{km}$ & 161.3 & 162.4 \\
\hline North latitude, degrees & 42.6 & 42.6 \\
\hline West longitude, degrees & 70.7 & 68.0 \\
\hline Solar zenith angle, degrees & 55.4 & 52.0 \\
\hline \multicolumn{3}{|c|}{ Satellite measured values at time of crossing } \\
\hline $\begin{array}{l}\mathrm{N}_{2} \text { density, } \mathrm{cm}^{-3} \\
\mathrm{O} \text { density, } \mathrm{cm}^{-3} \\
\text { He density, } \mathrm{cm}^{-3} \\
\text { Electron Temperature, } \mathrm{K} \\
\text { Electron density, } \mathrm{cm}^{-3} \\
\text { Neutral Temperature, } \mathrm{K}\end{array}$ & $\begin{array}{l}1.29 \times 10^{10} \\
1.25 \times 10^{10} \\
2.48 \times 10^{7} \\
1050 \\
1.33 \times 10^{5}\end{array}$ & $\begin{array}{l}1.06 \times 10^{10} \\
1.18 \times 10^{10} \\
2.13 \times 10^{7} \\
1110 \\
1.48 \times 10^{5} \\
702\end{array}$ \\
\hline \multicolumn{3}{|l|}{ Millstone Hill determined parameters } \\
\hline $\begin{array}{l}\text { Exospheric temperature, } \mathrm{K} \\
\text { Temperature at } 120 \mathrm{~K}\end{array}$ & $\begin{array}{l}790 \pm 18 \\
350 \pm 13\end{array}$ & $\begin{array}{l}779 \pm 13 \\
301 \pm 11\end{array}$ \\
\hline $\begin{array}{l}\text { Shape parameter in lower } \\
\text { thermosphere } S, \mathrm{~K} \mathrm{~cm}^{-1}\end{array}$ & $0.053 \pm 0.008$ & $0.046 \pm 0.006$ \\
\hline $\begin{array}{l}\text { Electron temperature, } \mathrm{K} \\
\text { at satellite crossing }\end{array}$ & $960 \pm 20(998)$ & $990 \pm 20(966)$ \\
\hline $\begin{array}{l}\text { Electron density, } \mathrm{cm}^{-3} \text {, } \\
\quad \text { at satellite crossing } \\
\mathrm{N}\left(\mathrm{O}^{+}\right) / N_{e} \text { at satellite crossing } \\
\mathrm{O} \text { density at satellite crossing, } \mathrm{cm}^{-3} \\
\text { Neutral Temperature, } \mathrm{K}\end{array}$ & $\begin{array}{c}1.85 \pm 0.05 \times 10^{5} \\
\left(1.50 \times 10^{5}\right) \\
0.15 \pm 0.07 \\
0.7 \pm 0.3 \times 10^{10} \\
737\end{array}$ & $\begin{array}{c}2.35 \pm 0.05 \times 10^{5} \\
\left(1.55 \times 10^{5}\right) \\
0.36 \pm 0.08 \\
1.2 \pm 0.4 \times 10^{10} \\
703\end{array}$ \\
\hline \multicolumn{3}{|l|}{ Geophysical parameters } \\
\hline $\begin{array}{l}\text { Solar F10.7 } \\
\text { Sunspot number } \\
A_{p}\end{array}$ & $\begin{array}{l}78.3 \\
26 \\
12\end{array}$ & $\begin{array}{l}85.8 \\
46 \\
4\end{array}$ \\
\hline
\end{tabular}
days on which the AE-C satellite passed over Millstone Hill.

With the temperature profile thus specified, we determine the vertical distribution of neutral density from the analytic profile of BATTS (1959) by requiring that the calculated $\mathrm{O}$ and $\mathrm{N}_{2}$ densities at $161 \mathrm{~km}$ agree with the satellite measurements of these constituents. The $\mathrm{O}_{2}$ number density at $120 \mathrm{~km}$ is specified as $5 \times 10^{10} \mathrm{~cm}^{-3}$, which gives an

Table 3. Parameters at the time of the AE satellite crossings of Millstone Hill

Values in parenthesis give model calculations 
$\mathrm{O}_{2}$ to $\mathrm{N}_{2}$ ratio of 0.12 at an altitude of $200 \mathrm{~km}$; this is consistent with the measurements of NIER et al. (1976).

The only other parameters necessary for the model calculation are the boundary conditions for the electron and ion energy equations and the $\mathrm{O}^{+}$ diffusion equation. The lower boundary of the model is at $80 \mathrm{~km}$, where the electron and ion temperatures are assumed to be equal to the neutral gas temperature. At the lower boundary the time-dependent ion chemistry equations are solved without diffusion and the resulting values are used to specify the ion number densities for the ion transport equations. The upper boundary of the model is set at $500 \mathrm{~km}$, the upper limit of the incoherent scatter radar data. The electron and ion heat fluxes are calculated from the temperature and temperature gradient measurements at $500 \mathrm{~km}$ and are used as upper boundary conditions for the electron and ion energy equations. The measured electron density is used as a boundary condition for the $\mathrm{O}^{+}$transport equation. The $\mathrm{O}^{+}, \mathrm{NO}^{+}$and $\mathrm{O}_{2}^{+}$ densities are determined according to the method of Schunk and WAlker (1973). Thus, the only specified parameters for these calculations are the solar EUV flux, the neutral atmospheric properties and the boundary conditions for the plasma energy and transport equations. The initial conditions are specified arbitrarily and the model is run to steady state in the daytime ionosphere, where photochemical time constants are fast. The minor neutral constituent chemistry, however, has a much longer time constant and its distribution can be influenced by neutral dynamic and transport processes. Realizing these limitations, we nevertheless present steady state calculations for comparison with the measured NO density.

\section{SATELLTTE MEASUREMENTS}

The satellite geographic longitude, geographic latitude, altitude and local solar time relationship for AE-C orbit 666 on 14 February 1974 are shown in Fig. 2. On the inbound pass, the satellite descended from $400 \mathrm{~km}$ near $68^{\circ} \mathrm{N}$ latitude to $160 \mathrm{~km}$ near $45^{\circ} \mathrm{N}$ latitude. It passed over Millstone Hill at $161 \mathrm{~km}$ and ascended to $300 \mathrm{~km}$ near $20^{\circ} \mathrm{N}$ latitude. The total change in latitude was $50^{\circ}$, and the total change in longitude was $60^{\circ}$. The local solar time varied between 0900 and 1300 along the satellite orbit, which covered the altitude range from $400 \mathrm{~km}$ to $160 \mathrm{~km}$ to $300 \mathrm{~km}$. The orbital parameters of the satellite at the time it crossed the latitude of Millstone Hill are summarized in Table 3.

Several instruments on board the AE-C satellite wcre used to measure various atmospheric parameters over Millstone Hill. The measurements made by neutral mass spectrometers (NIER et al., 1973; PELz et al., 1973) were used to specify the neutral composition, ion mass spectrometers (Brinton et al., 1973) specified ion composition along the satellite path and the retarding-potential analyzer (HANSON et al., 1973) gave the ion temperature and density, A cylindrical electrostatic probe (BRACE et al., 1973) was used to specify the electron density and temperature along the satellite

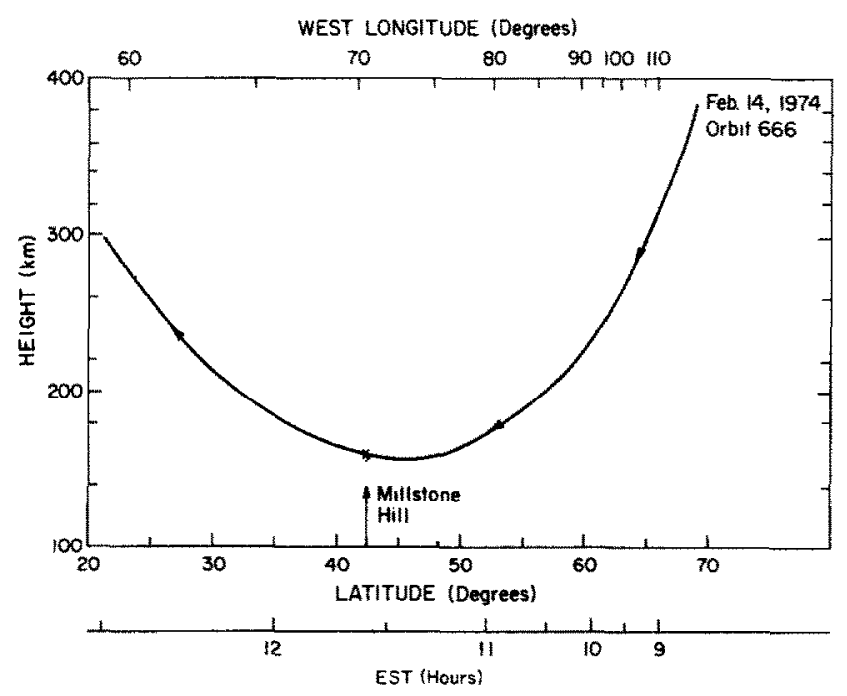

Fig. 2. The longitude, latitude, local solar time and height relationships for the inbound and outbound pass of AE-C satellite orbit 666 on 14 February 1974. 
path and the neutral-atmosphere temperature instrument (SPENCER et al., 1973) was used to measure the neutral gas temperature. The solar EUV flux was measured by the EUV spectrophotometer (Hinteregaer et al., 1973). The $6300 \AA$ volume emission rate profile was determined by the visible airglow experiment (HAYs et al., 1973), and the nitric oxide distribution was obtained from the UV spectrometer measurements (BARTH et al., 1973). Finally, the photo-electron-spectrometer (DoERING et al., 1973) was used to determine the photoelectron spectra at the time of the AE-C crossing over Millstone Hill.

\section{RADAR MEASUREMENTS}

The vertically directed UHF (ultra-high frequency; $440 \mathrm{MHz})$ radar at Millstone Hill $\left(42.6^{\circ} \mathrm{N}\right.$, $71.5^{\circ} \mathrm{W}$ ) was used to make incoherent scatter measurements during the overflights of AE-C on orbits 666 and 677 . The observations were conducted with the 'two-pulse' program in which pairs of short radar pulses, whose separation is varied, are transmitted during each sweep. A full cycle of operations using basic pulse lengths of 40,100 and $200 \mu \mathrm{s}(6,15$ and $30 \mathrm{~km}$ height resolution, respectively) required about $30 \mathrm{~min}$ and covered the altitude range from 100 to $500 \mathrm{~km}$.

The incoherent scatter signal is processed to determine total power and correlation functions at a number of altitudes. The power measurements permit an altitude profile of electron density to be calculated after normalization to the peak density by using ionosonde records of foF 2 . If the ion composition is known, both the electron and ion temperatures can be determined directly from the shape of the measured incoherent scatter correlation functions. Direct determination can be made between 115 and $130 \mathrm{~km}$, where the dominant ions are $\mathrm{NO}^{+}$and $\mathrm{O}_{2}^{+}$(we assume an ion mass of $31 \mathrm{amu}$ ), and also from 225 to $500 \mathrm{~km}$, where $\mathrm{O}^{+}$is the dominant ion. Between 130 and $225 \mathrm{~km}$ only two of the three unknowns $\left(T_{e}, T_{i}\right.$ and $q=$ $\left.\mathrm{N}\left(\mathrm{O}^{+}\right) / \mathrm{N}_{\mathrm{e}}\right)$ can be determined from the measurements, since there is a transition from molecular ions $(q=0)$ to atomic ions $(q=1)$. Our method of resolving this problem was to construct a model of neutral temperature, $T_{n}$, by using only the data outside the transition region, where $T_{e}$ and $T_{i}$ are easily determined, and then predicting $T_{n}$ over the transition region heights from this model. Since $T_{i}=T_{n}$ over the transition altitude range, in effect we had determined $T_{i}$. The remaining unknowns, $T_{c}$ and $q$, are obtained directly from the measured correlation functions.
For the $T_{n}$ model the BATEs (1959) form is adopted,

$$
T_{n}(h)=T_{\infty}-\left(T_{\infty}-T_{0}\right) \exp \left(-s\left(h-h_{0}\right)\right)
$$

where $h$ is altitude and $h_{0}=120 \mathrm{~km}$. Under daytime conditions the unknowns $T_{\infty}, T_{0}$ and $s$ are found by using $T_{i}$ (i.e. $T_{n}$ ) for altitudes between 115 and $130 \mathrm{~km}$, and $T_{i}, T_{e}$ and $N_{e}$ (together with the heat balance equation for the ion gas) over the altitude range from 225 to $425 \mathrm{~km}$ (SALAH and Evans, 1972). The fitting procedure also allows a fourth parameter to be determined: the concentration of atomic oxygen (assumed to be in diffusive equilibrium) at a reference altitude of $400 \mathrm{~km}$.

Table 3 summarizes results from the $30 \mathrm{~min}$ of incoherent scatter data collected during the AE-C passes on orbits 666 and 677 . Since the atomic oxygen concentration and ion composition cannot be determined as accurately as the other variables from the incoherent scatter measurements, the values given in Table 3 for these two parameters represent averages over three $30 \mathrm{~min}$ runs.

\section{RESULTS}

\section{(a) Electron density}

The electron density profile measured by the Millstone Hill incoherent scatter radar at the time of the AE-C satellite crossing of Millstone Hill on orbit 666 is shown as the solid line without arrows in Fig. 3. The electron density peak occurs at a value of about $4.5 \times 10^{5} \mathrm{~cm}^{-3}$ at an altitude of $230 \mathrm{~km}$ and is characteristic of a typical daytime profile ubserved over Millstone Hill for conditions near solar minimum. The electron density profile calculated by the ionospheric model is shown as the dashed line in Fig. 3 ; its peak is about $5 \times 10^{5} \mathrm{~cm}^{-3}$ but at an altitude near $250 \mathrm{~km}$. The difference in altitude probably occurred because the polewarddirected neutral wind flowing in the thermosphere could have been stronger at the time of the measurement than the wind used in the model calculations. In the model the wind at the F2-peak is directed toward the pole with a speed of $25 \mathrm{~m} \mathrm{~s}^{-1}$ at 1130 LT. This is typical of daytime thermospheric winds; however, the results suggest that we would obtain better agreement by increasing the speed of the model thermospheric winds to $50 \mathrm{~m} \mathrm{~s}^{-1}$. These differences between calculated and observed values are not significant. The $\mathrm{AE}-\mathrm{C}$ satellite measurements of electron density along the satellite path are shown in Fig. 3 as the solid line with arrows. The electron density measured directly over Millstone Hill is shown as a cross at $161 \mathrm{~km}$. There is 


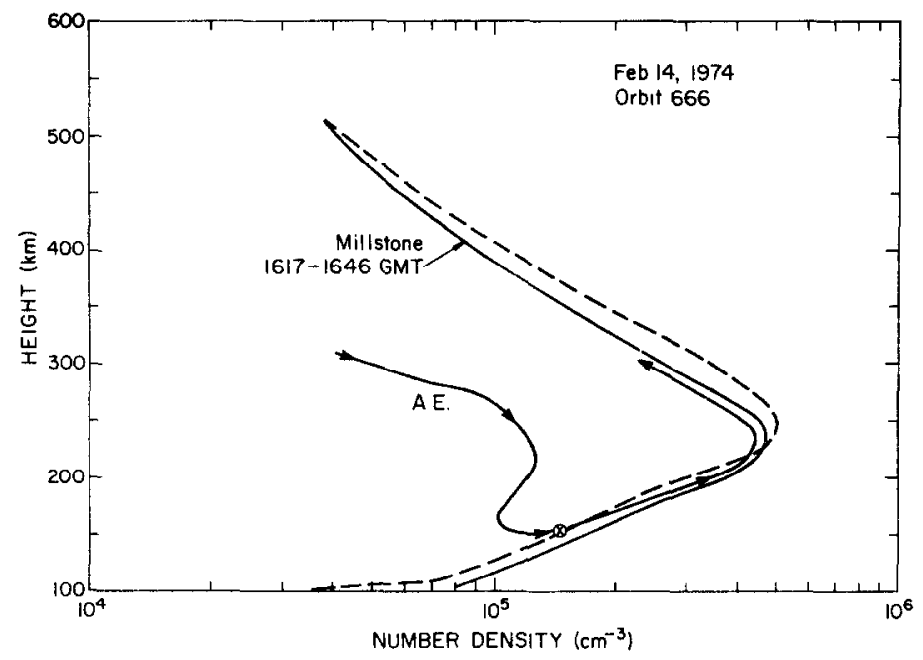

Fig. 3. Electron number density profile over Millstone Hill at the time of the AE-C crossing on orbit 666,14 February 1974 . The solid line is the density profile measured by the incoherent scatter radar, the dashed line gives the density profile calculated by the ionospheric model and the solid line with arrows shows the AE-C satellite measurements along the satellite path.

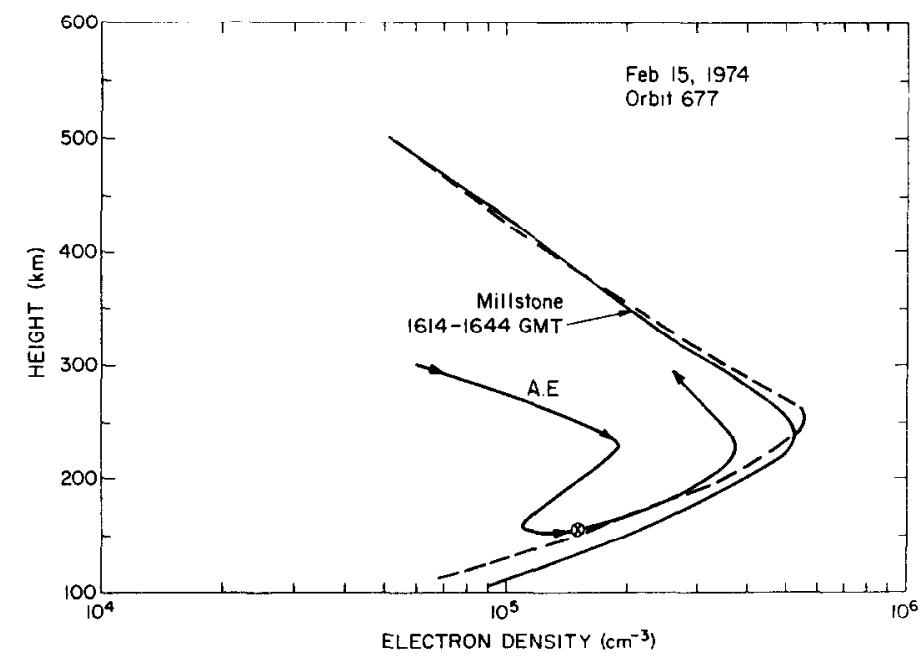

Fig. 4. Same as in Fig. 3, for orbit 677 on 15 February 1974.

considerable latitudinal and longitudinal variation evident in the measurements. However, there is general agreement among the satellite measurements, the incoherent scatter radar measurements and the model calculations of electron density over Millstone Hill at $161 \mathrm{~km}$. Similar agreement among incoherent scatter radar measurements, model calculations and satellite measurements of electron density was obtained for AE-C satellite orbit 677 on 15 February 1974 (Fig. 4). On orbit 677 the satellite measurements again show considerable latitudinal and longitudinal variability along the satellite path in contrast to a vertical profile at a given location.

\section{(b) Ion densities}

The ion chemistry profiles of $\mathrm{O}^{+}, \mathrm{O}_{2}^{+}$and $\mathrm{NO}^{+}$ for AE-C orbit 66 are shown in Fig. 5. The dashed lines show model calculations for the time of the satellite crossing over Millstone Hill and the solid lines with arrows show satellite measurements of ion density along the satellite path. The breaks in the solid line indicate data gaps along the orbital path. There is reasonable agreement between the 


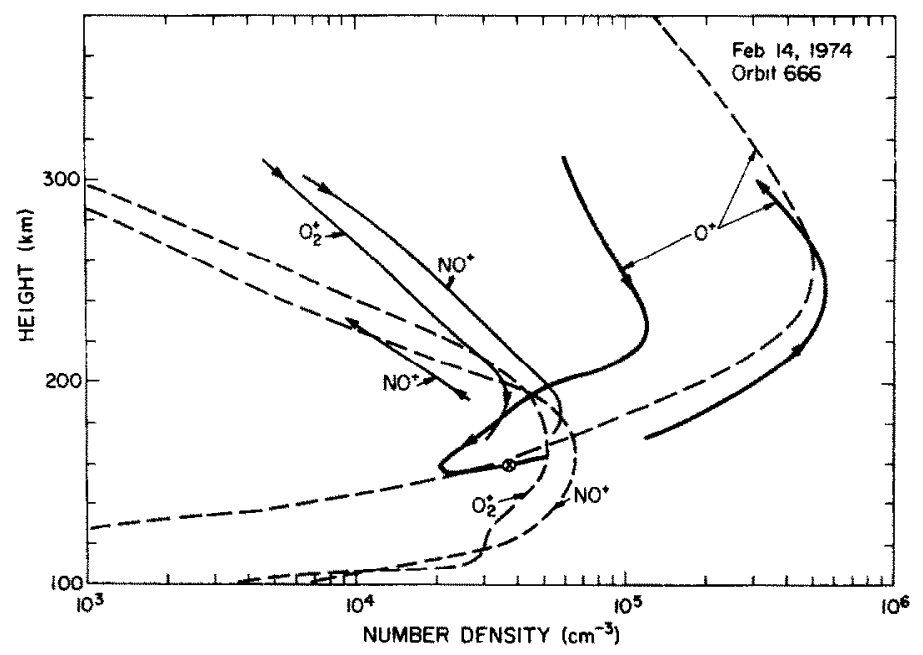

Fig. 5. Ion density profiles calculated over Millstone Hill at the time of the AE-C satellite crossing and ion densities measured along the satellite path. The dashed lines are the ionospheric model calculations and the solid lines with arrows are the satellite measurements along the satellite path. The breaks in the solid lines with arrows indicate regions where satellite data were missing.

calculated and observed $\mathrm{O}^{+}$density at the satellite crossing at $161 \mathrm{~km}$ over Millstone Hill. However, there is also considerable latitudinal and longitudinal variation along the satellite path. At a given altitude densities at high latitudes are lower than they are at low latitudes. The $\mathrm{O}_{2}{ }^{+}$and $\mathrm{NO}^{+}$ion densities were obtained during only a portion of the orbital pass and measurements were not obtained at the Millstone Hill crossing at $161 \mathrm{~km}$. The apparent discrepancy between the measured and calculated $\mathrm{NO}^{+}$and $\mathrm{O}_{2}^{+}$scale heights is due to latitudinal changes in composition and temperature. When applied point-by-point along the satellite path, the model in fact closely reproduces the satellite measurements. The incoherent scatter measurements give $\mathrm{N}\left(\mathrm{O}^{+}\right) / \mathrm{N}_{\mathrm{e}}=0.15 \pm 0.07$ at $161 \mathrm{~km}$, compared to values of 0.21 from the model calculation and 0.29 from AE-C measurements.

\section{(c) Electron and ion temperatures}

The calculated and observed profiles of electron and ion temperatures and the neutral gas temperature for the $\mathrm{AE}-\mathrm{C}$ crossing of Millstone Hill on orbit 666 are shown in Fig. 6. The incoherent scatter radar measurements are indicated by crosses with error bars and the solid line is a smooth fit to the data. The dashed lines show model calculations for the same time. The electron and ion heat fluxes at $500 \mathrm{~km}$, determined from the observed values, are used as boundary conditions for the electron

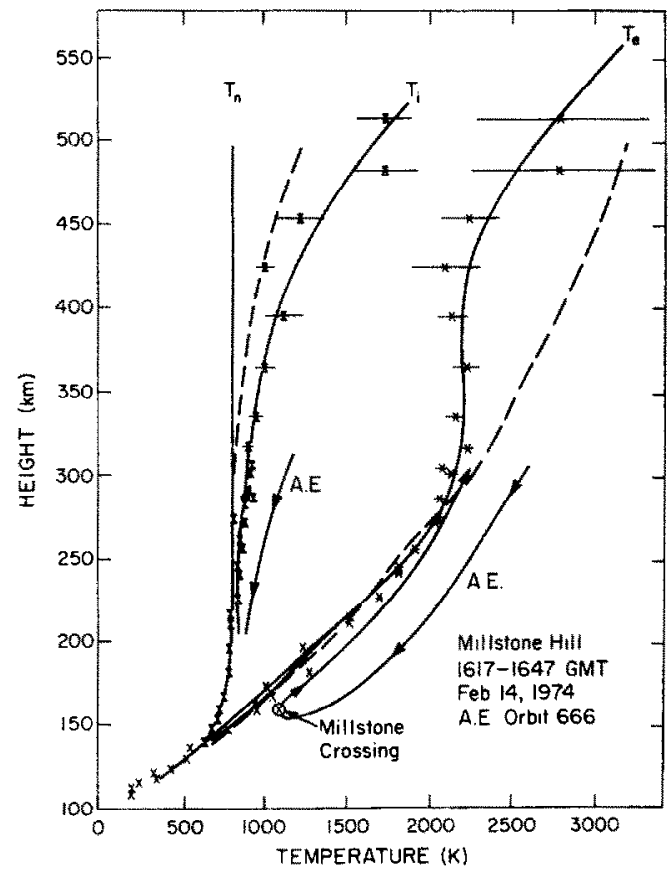

Fig. 6. Electron, ion and neutral gas temperature profiles over Millstone Hill for the time of the AE-C satellite crossing on orbit 666,14 February 1974 . The crosses are incoherent scatter radar measurements and the solid lines are smooth fits to the data. The dashed lines are ionospheric model calculations and the solid line with arrows gives the AE-C satellite measurements along the satellite path. The circled crosses represent the AE-C measurements at $161 \mathrm{~km}$ over Millstone Hill. 
and ion energy equations. The collisional loss processes in the energy equations are the same as those given in Rees and Roble (1975) and Roble and Hastings (1977) except that we used the atomic oxygen fine structure electron loss rate derived by HoEgy (1976) in the calculations. Below $300 \mathrm{~km}$ there is good agreement between the electron temperatures determined by the incoherent scatter radar and by the model calculations. The AE-C satellite measurements of the electron and ion temperatures were generally higher than both the incoherent scatter radar measurements and the model calculations. At the only place where overlapping data occur, over Millstone Hill at $161 \mathrm{~km}$, the incoherent scatter radar measured an electron temperature of $960^{\circ} \mathrm{K}$, the satellite measured a value of $1050^{\circ} \mathrm{K}$ and the model calculations gave $998^{\circ} \mathrm{K}$. The spread of $90^{\circ} \mathrm{K}$ in the measured and calculated electron temperatures is not considered significant since measurements and model calculations were made in an altitude region with large temperature gradients. The satellite measurements of ion temperatures, although not directly measured over Millstone Hill at $161 \mathrm{~km}$, do bracket the incoherent scatter radar observations at higher altitudes with the measurements made by AE-C on its inbound and outbound passes.

Above $300 \mathrm{~km}$, there is a significant difference between the calculated electron temperature and the electron temperature determined by the incoherent scatter radar. Such a difference between calculated and observed electron temperatures also was occasionally noted by Brace et al. (1976). This effect could be caused by an inaccurate description of the $\mathrm{H}^{+}$density in the topside ionosphere by the ionospheric model for 14 February 1974 . If the $\mathrm{H}^{+}$ densities were greater than the chemical equilibrium densities calculated by the ionospheric model, the increased $\mathrm{H}^{+}$density would act to decrease the electron temperature and increase the ion temperature through coulomb collision between $\mathrm{H}^{+}$ions and electrons. This would give better agreement between the calculated and observed profiles. However, the shapes of the incoherent scatter correlation functions are markedly changed even if only a small amount of $\mathrm{H}^{+}$is present along with the dominant $\mathrm{O}^{+}$ions. For the present measurements, there is no indication of any $\mathrm{H}^{+}$below $500 \mathrm{~km}$, within the detection limit of about $2 \%$. The electron and ion temperatures observed on the 30-min runs prior to and after the AE-C pass on orbit 666 show better agreement with model predictions, although some discrepancy remains.

For the next day, 15 February 1974, the calcu- lated and observed electron temperature profiles above $300 \mathrm{~km}$ over Millstone Hill were in better agreement (Fig. 7). It is not clear why the agreement was better on 15 February, but perhaps the $\mathrm{H}^{+}$density was different. At these altitudes chemical equilibrium between $\mathrm{H}^{+}$and $\mathrm{O}^{+}$should prevail, which suggests a change in the neutral hydrogen distribution because the electron density and atomic oxygen density were similar for the two calculations.

The AE-C electron temperature measurements along the satellite path are shown in Fig. 7 as a solid line, with arrows to indicate the inbound and outbound portions of the satellite pass. The satellite measurements show nearly equal temperature gradients for both the inbound and outbound passes, in contrast to the somewhat different gradients observed on orbit 666 . The differences were probably due to variations in the heat flow rate of the electron gas from the magnetosphere along the satellite path. There is a spread of $144 \mathrm{~K}$ among the electron temperatures observed by the incoherent scatter radar and the AE-C satellite and calculated by the ionospheric model at $162 \mathrm{~km}$, the altitude of the AE-C satellite crossing over Millstone Hill (Table 3). The incoherent scatter radar measured a temperature of $990 \mathrm{~K}$, the AE-C satellite measured $1110 \mathrm{~K}$ and the calculated temperature was $966 \mathrm{~K}$. Again, the measurements were made in a region where large temperature gradients exist.

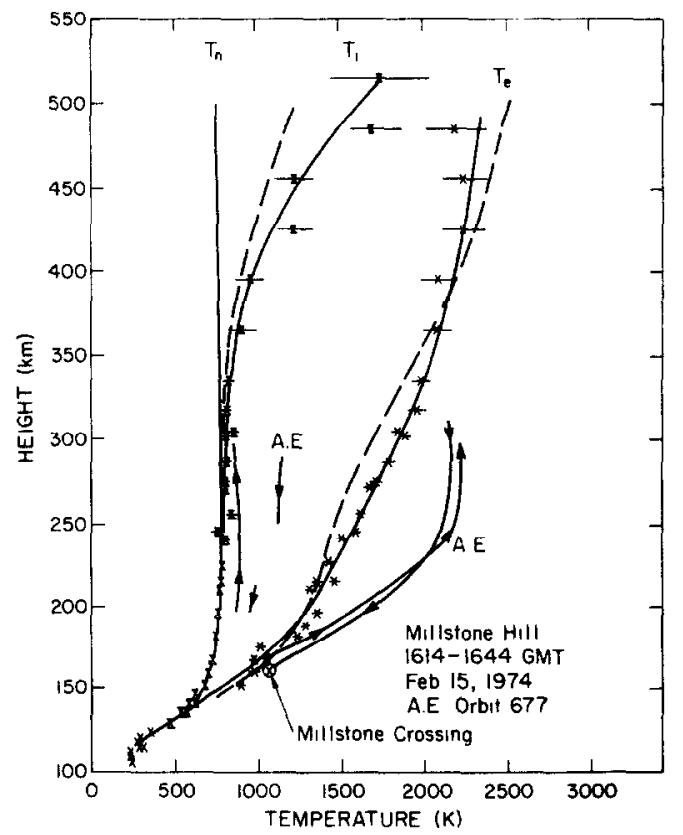

Fig. 7. Same as for Fig. 6, for orbit 677 on 15 February 1974. 


\section{(d) Neutral temperature}

The neutral gas temperature profile measured by the AE-C satellite is in good agreement with the neutral gas profile determined by the incoherent scatter radar measurements. The satellite measured a temperature of $702 \mathrm{~K}$ over Millstone Hill on orbit 677 in contrast to a temperature of $703 \mathrm{~K}$ measured by the incoherent scatter radar as given in (Table 3).

\section{(e) OI $6300 \AA ̊$ emission rate}

The $6300 \AA$ volume emission rate at the time of the AE-C satellite crossing over Millstone Hill was observed by the visible airglow experiment photometer (Hays et al., 1973) and is shown in Fig. 8. The dots give the actual data points and the solid line is a smooth fit to the data. The data are an average of about 30 limb scans by the VAE photometer in the vicinity of Millstone Hill. We inverted the data to obtain the volume emission rate profile using the Abel Inversion technique described by Hays et al. (1977). The $6300 \AA$ volume emission rate was observed to peak at $220 \mathrm{~km}$ with a value of 250 photons $\mathrm{cm}^{-3} \mathrm{~s}^{-1}$. The calculated total $6300 \AA$ volume emission rate above Millstone Hill is shown as the dashed line in Fig. 8; and the various components contributing to the total $6300 \AA$ volume emission rate are also shown. The components are excitation due to dissociative recombination, Schumann-Runge photodissociation, photoelectron impact and thermal electron impact. The various reaction rates, quenching cocfficients and excitation cross sections that we used in the analysis were discussed in detail by RoBLE et al. (1976) and Hays et al. (1977). Above $350 \mathrm{~km}$, thermal electron impact is the major source of $6300 \AA$ excitation. However, its total contribution is only $23 \mathrm{R}$ (Rayleighs). Between 200 and $350 \mathrm{~km}$, photoelectron impact and chemical recombination are the major excitation sources; they contribute a total of $1193 \mathrm{R}$ and $799 \mathrm{R}$, respectively. And, below $200 \mathrm{~km}$, Schumann-Runge photodissociation is the major excitation source, with a total intensity of $1498 \mathrm{R}$. The total $6300 \AA$ emission rate calculated at the time of the AE-C satellite crossing of Millstone Hill was $3721 \mathrm{R}$; the calculated vertical profile of the $6300 \AA$ volume emission rate shows good agreement with the measured values.

\section{(f) Odd nitrogen}

The calculated steady state distribution of minor neutral constituents at the time of the AE-C satellite crossing of Millstone Hill is shown in Fig. 9. The chemical reactions and reaction rates used in the calculation are given in Table 1. The AE-C satellite measurements of the NO distribution along

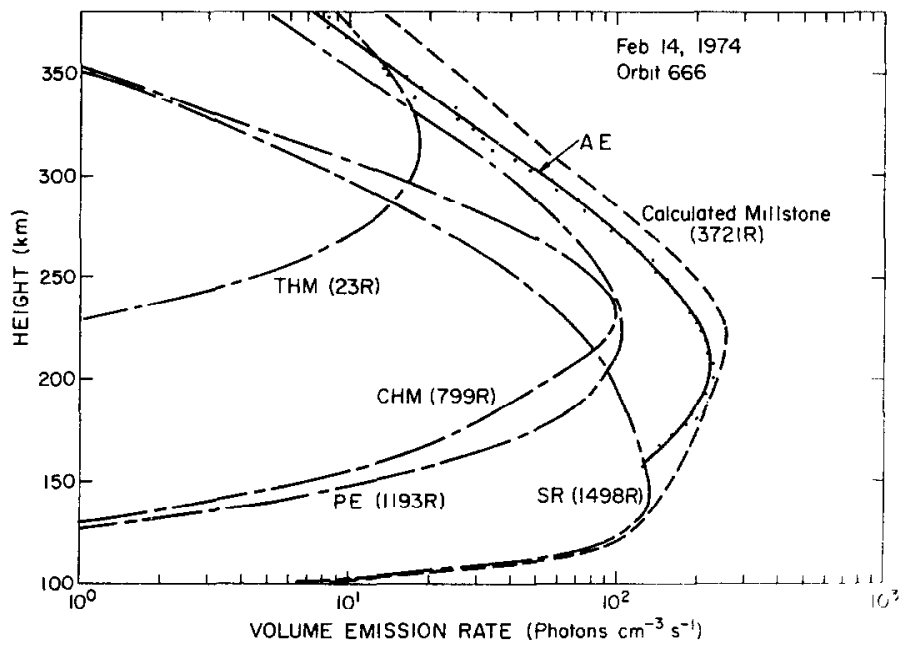

Fig. 8. Calculated and observed $6300 \AA$ volume cmission ratc. The dots show the $6300 \AA$ volume emission rates observed by the visible airglow experiment aboard the AE-C satellite over Millstone Hill. The solid line is a smooth fit to the data points. The dashed line shows the total $6300 \AA$ volume emission rate calculated by the ionospheric model. The long and short dashed lines show various components of the $6300 \AA$ volume emission rate; THM, excitation of atomic oxygen by thermal electron impact; CHM, dissociative recombination; PE, photoelectron impact; SR, Schumann-Runge photodissociation. 


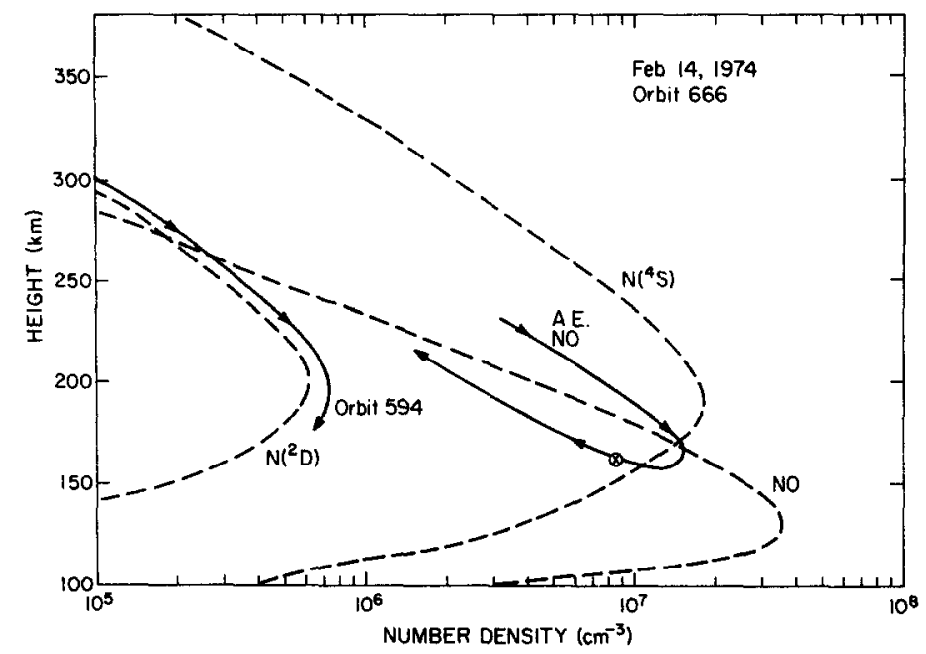

Fig. 9. Nitric oxide distribution measured by the AE-C satellite (solid line) and distribution of the minor neutral constituents $\mathrm{N}\left({ }^{4} S\right), \mathrm{N}\left({ }^{2} D\right)$ and $\mathrm{NO}$ calculated by the ionospheric model at the time of the AE-C satellite crossing of Millstone Hill on orbit 666 on 14 February 1974. The cross indicates the measured NO density over Millstone Hill.

the satellite path are shown as a solid line with arrows to indicate the inbound and outbound satellite passes. The NO density measured directly over Millstone Hill is shown as a cross at $160 \mathrm{~km}$ and has a value of $9 \times 10^{6} \mathrm{~cm}^{-3}$. The model calculations gave $1.6 \times 10^{7} \mathrm{~cm}^{-3}$ for the NO number density at $160 \mathrm{~km}$. The AE-C measurements of NO bracket the calculated values, indicating reasonable agreement between model calculations and measurements from the satellite pass. The measured NO densities are also consistent with the values of $\mathrm{NO}^{+}$ shown in Fig. 5, with high values on the inbound and low values on the outbound portion of the orbit. The discrepancies may be due in part to transport by winds and in part to deficiencies in the photochemical theory of minor neutral constituent chemistry. No measurements of $\mathrm{NO}$ or $\mathrm{N}\left({ }^{2} D\right)$ density were made during AE-C orbit 677 . However, an $\mathrm{N}\left({ }^{2} D\right)$ density profile was determined from the $5200 \AA$ airglow measurements on AE-C orbit 594 (Frederick and Rusch, 1977) and it is shown in the figure for the sake of comparison. The calculated densities, although obtained for a different but comparable orbit, are somewhat greater than model calculations although the agreement is generally good.

\section{(g) Photoelectron spectrum}

Our last comparison was between the measured and calculated photoelectron spectra over Millstone Hill at the time of the AE-C satellite crossing. The calculated and observed photoelectron spectra for orbit 666 on 14 February and orbit 677 on 15 February are shown in Figs. 10 and 11, respectively. The solid line is the calculated total photoelectron flux, which consists of the sum of the

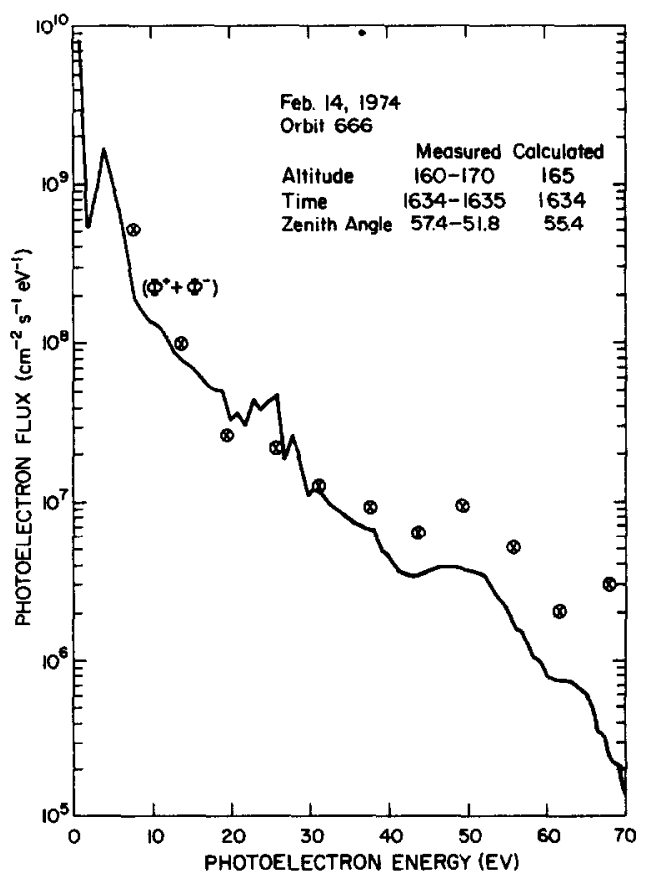

Fig. 10. Photoelectron flux spectra measured by the AEC satellite during the Millstone Hill crossing on orbit 666 , 14 February 1974 (crosses) and calculated by the ionospheric model (solid line). 


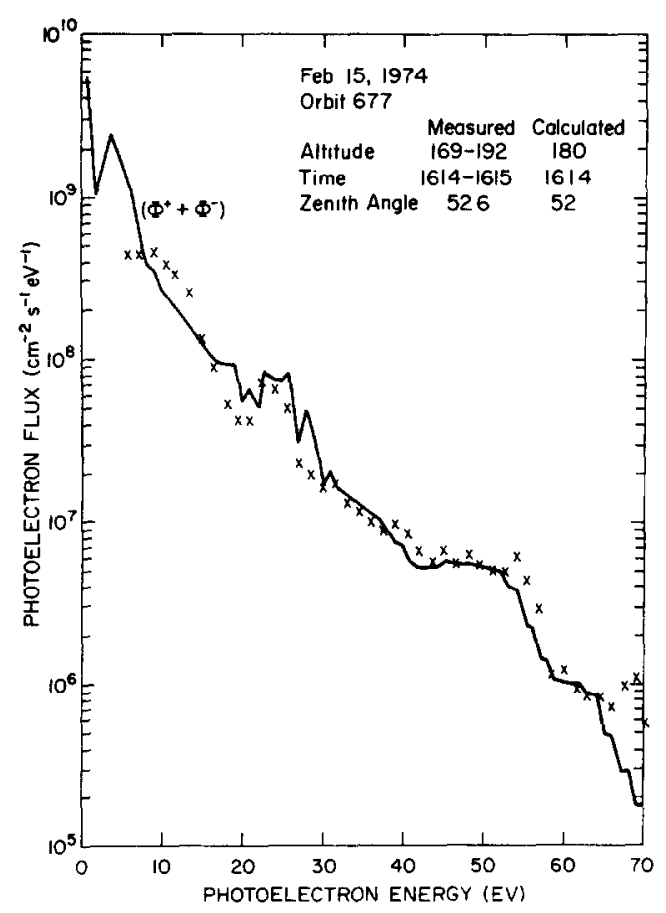

Fig. 11. Same as in Fig. 10, for AE-C satellite orbit 677 on 15 February 1974.

upward- and downward-directed photoelectron streams in the NAGY and BANKS (1970) program. These photoelectron fluxes were assumed to be isotropic for the purpose of comparison to AE-C measurements. On orbit 666 the photoelectron spectrum was calculated at $165 \mathrm{~km}$ and on orbit 677 the spectrum was calculated at $180 \mathrm{~km}$. The measurements, shown as crosses in both figures, were obtained over the altitude range shown on the figure insert. On orbit 666 the photoelectron spectrum was obtained at a $6 \mathrm{eV}$ resolution, whereas the photoelectron spectrum on orbit 677 was obtained at a higher resolution of $1.5 \mathrm{eV}$. In both cases the agreement between the calculated and observed values is generally good.

\section{DISCUSSION}

The results described above indicate that current $F$-region theory, as described by model computations, is adequate for describing the measured ionospheric properties in the mid-latitude daytime ionospheric region where photochemical processes dominate. The measurements and calculations apply to a low level of solar activity near solar minimum, with solar F10.7 values of $70-80 \times$ $10^{-22} \mathrm{~W} \mathrm{~cm}^{-2} \mathrm{~Hz}^{-1}$. When used in the ionospheric model, the measured values of the solar EUV flux, as discussed by HinteregGer (1975), give a calculated ionospheric structure that generally agrees with observations for the two days that we analyzed.

Our results also show that there is considerable variation in the ionospheric properties along the satellite path and that care should be taken in converting the satellite data into height profiles for comparison with ground-based measurements. Some of the variations are associated with latitudinal gradients of neutral composition and dynamics and some are associated with the satellite's passing through regions (for example, high latitudes) where processes other than solar photochemistry are operating.

Acknowledgements--The National Center for Atmospheric Research is sponsored by the National Science Foundation. Millstone Hill received support from the National Science Foundation under Grant GA-42230. Financial support was provided by NASA contract NAS5-11405 (A. I. S.), NASA contract NA5-5-23006 (D. W. R.) and NASA grant NAS-5-20705 to Cornell University (M. R.T ).
Banks P. M.

Barth C. A., Rusch D. W. and Stewart A. I.

BAtes D. R.

Black G., Slanger T. G., St. John G. A. and Young R. A.

Brace L. H., Theis R. F. and Dalgarno A.

Brace L. H., Hoegy W. R., Mayr H. G., HANSON W. B., Reber C. A. and HiNTEREgGer H. E.

Brinton H. C., Scott L. R., Pharo III, M. W. and Coulson J. T.

Dalgarno A.

Dalgarno A., Hanson W. B., Spencer N. W. and SCHMENLING E. R.

Doering J. P., Bostrom C. O. and Armstrong J. C.

\section{REFERENCES}

Planet. Space Sci. 15, 77.

Radio Sci. 8, 379.

Proc. $R$. Soc. B64, 805.

J. Chem. Phys. 51, 116.

Radio Sci. 8, 341.

J. geophys. Res. 81, 5421.

Radio Sci. 8, 323.

Annls Géophys. 26, 601.

Radio Sci. 8, 263.

Radio Sci. 8, 387. 
Evans J. V.

FEhSENFEld F. V., Dunkin D. B. and Ferguson E. E.

Frederick J. E. and Rusch D. W.

GASTRANG R. H.

Goldan P. D., Schmeltekopf A. L., Fehsenfeld

F. C., SChIFF H. I. and FERguson E. E.

Hanson W. B., Zuccaro D. R., Leppencott C. R. 1973 and Sanatani $S$.

Hastings J. T. and Roble R. G.

Hays P. B.., Carignan G., Kennedy B. C., Shepherd G. G. and WAlder J. C. G.

Hays P. B., Roble R. G., Rusch D. W., Tow M. R. and WALkER J. C. G.

Henry R. J. W., Burke P. G. and

SinfaIlanA A. L.

HINTEREGGER H. E.

HINTEREGGer H. E.

Hinteregger H., Bedo D. E. and Manson J. E.

HOEGY W. R.

LIN C. L. and KaUfman F.

Lindinger W., Albritton D. C., Fehsenfeld F. C. and Ferguson E. E.

Lindinger W., Fehsenfeld F. C., Schmeltekopf A. L. and Ferguson E. E.

McFarland M., Albritton D. C., Fehsenfeld F. C., Ferguson E. E. and

SCHMELTEKOPF A. L.

McFarland M., Albritton D. C., Fehsenfeld F. C., Ferguson E. E. and SCHMELTEKOPF A. L.

NAGY A. F. and BANKS P. M.

Nier A. O., Potter W. E., Hickman D. R. and MAuersberger, $\mathrm{K}$.

Nier A. O.. Potter W. E. and Kayser D. C.

Oran E. S., Julienne P. S. and Strobel D. F.

Orsini N., Torr D. G., Brinton H. C., Brace L. HL, Nifr A. O. and Walker J. C. G.

Pelz D. T., Reber C. A., Hedin A. E. and Carignan G. R.

Phillips L. F. and SCHifF H. I.

ReEs M. H. and Roble R. G.

ROBLE R. G.

Roble R. G. and Hastings J. T.

Roble R. G., Noxon J. F. and Evans J. V.

Roble R. G. and Rees M. H.

Rusch D. W., Stewart A. I., Hays P. B. and HOFFMAN J. H.

Rutherford J. A. and VROOM D. A.

Salah J. E. and Evans J. V.

SCHUNK R. W. and Walker J. C. G.

Spencer N. W., Niemann H. B. and Carignan G. R. 1973

Stot.arski R. S., Hays P. B. and Robi.f. R. G.

STROBEL D. F.

TORR D. G., TORR M. R., Walker J. C. G. and NiER A. O.

WILSON W, E.

WINTERS H. F.
Proc. IEEE 57, 496

Planet. Space Sci. 18, 4267.

Rev. Geophys. Space Phys. 12, 703.

J. geophys. Res. (in press).

Airglow Aid Aurorae. Pergamon Press, N.Y.

J. Chem. Phys. 44, 4095.

Radio Sci. 8, 333.

Planet. Space Sci. 25, 209.

Radio Sci. 8, 369.

J. geophys. Res. (in press).

Phys. Rev. 178, 218.

Annls Géophys. 36, 547.

J. atmos. terr. Phys. 38, 791.

Radio Sci. 8, 349.

Geophys. Res. Lett. 3, 541.

J. Chem. Phys. 55, 3760.

J. geophys. Res. 80, 3725 .

J. geophys. Res. 79, 4753.

J. Chem. Phys. 59, 6620.

J. geophys. Res. 79, 2925.

J. geophys. Res. 75, 6260 .

Radio Sci. 8, 271.

J. geophys. Res. 81, 17.

J. geophys. Res. 80, 3068 .

Geophys. Res. Lett.

Radio Sci. 8, 277.

J. Chem. Phys. 36, 1509.

Rev. Geophys. Space Phys. 13, 201.

Planet. Space Sci. 23, 1017.

Planet. Space Sci. 25, 217.

Planet. Space Sci. 24, 327.

Planet. Space Sci. (in press).

J. geophys. Res. 80, 2300.

J. Chem. Phys. 55, 5622.

Space Research XIII, p. 267. Akademie-Verlag, Berlin.

Planet. Space Sci. 21, 1875.

Radio Sci. 8, 287.

J. geophys. Res. 80, 2266.

1971 J. geophys. Res. 76, 2441.

1976 J. geophys. Res. (in press).

1967 J. Chem. Phys. 46, 2017.

1966 J. Chem. Phys. 44, 1472. 